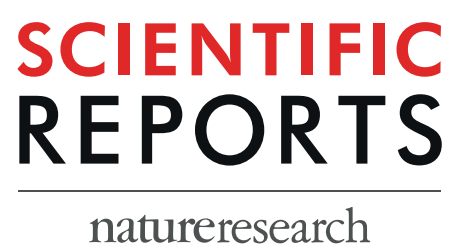

\title{
OPEN Mitigation of acyl-homoserine lactone (AHL) based bacterial quorum sensing, virulence functions, and biofilm formation by yttrium oxide core/shell nanospheres: Novel approach to combat drug resistance
}

\begin{abstract}
Fohad Mabood Husain ${ }^{1 *}$, Anees A. Ansari ${ }^{2 *}$, Aslam Khan ${ }^{2}$, Naushad Ahmad $^{3}$, Abdulrahman Albadri ${ }^{4}$ \& Thamer H. Albalawi ${ }^{5}$

The present study evaluated the efficacy of $\mathrm{Y}_{2} \mathrm{O}_{3}: \mathrm{Tb}$ (core) and $\mathrm{Y}_{2} \mathrm{O}_{3}: \mathrm{Tb} @ \mathrm{SiO}_{2}$ nanospheres (core/ shell NSs) against virulence functions regulated by quorum sensing (QS) and biofilm formation in pathogenic bacteria. Scanning electron microscope (SEM) images were used to study the size, shape, and morphology. The images clearly displayed spherical shaped, mono-dispersed particles with narrow size distribution and an average grain size of $110-130 \mathrm{~nm}$. The chemical composition of the samples was determined by using energy dispersive X-ray (EDX) and X-ray photoelectron spectroscopy (XPS). We determined the impact of core and core/shell NSs on QS using sensor strains of Chromobacterium violaceum CVO26 and Pseudomonas aeruginosa PAO1 in a comparative study. Sub-MICs of core and core/shell NSs substantially suppressed QS-controlled violacein production in C. violaceum. Similar concentration-dependent effect of sub-MICs of synthesized core and core/shell NSs was observed in the QS-regulated virulence functions (elastase, total protease, pyocyanin production, swarming motility, and exopolysaccharide production) in PAO1. A concentration-dependent decrease (14-60\%) was recorded in the biofilm forming capability of PAO1, upon treatment with core and core/shell NSs. Moreover, core/shell NSs were more effective in inhibiting biofilm at higher tested concentrations as compared to core-NSs. The synthesized NSs demonstrated significantly impaired attachment of cells to the microtiter plate indicating that NSs target biofilm inhibition at the attachment stage. Based on these results, we predict that core and core/shell NSs may be an alternative to combat the threat of drug-resistant pathogenic bacteria.
\end{abstract}

The emergence and spread of multidrug-resistance in bacteria has led to a multi-fold increase in mortality and morbidity globally ${ }^{1}$. Antibiotic resistance is considered one of the biggest threats to global health and is expected to have a huge economic impact ${ }^{2-4}$. The emergence of bacterial strains resistant to most of the currently available antibiotics is alarming ${ }^{5,6}$. On the other hand, there has been no major breakthroughs in the field of new

\footnotetext{
${ }^{1}$ Department of Food Science and Nutrition, College of Food and Agriculture Sciences, King Saud University, Riyadh, 11451, Saudi Arabia. ${ }^{2}$ King Abdullah Institute for Nanotechnology, King Saud University, Riyadh, 11451, Saudi Arabia. ${ }^{3}$ Department of Chemistry, College of Science, King Saud University, Riyadh, 11451, Saudi Arabia. ${ }^{4}$ National Center for Nanotechnology and Advanced Materials, King Abdulaziz City for Science \& Technology, Riyadh, 11442, Saudi Arabia. ${ }^{5}$ Department of Biology, College of Science and Humanities, Prince Sattam bin Abdulaziz University, Alkharj, 11942, Kingdom of Saudi Arabia. *email: fhusain@ksu.edu.sa; amustaqeemahmad@ksu.edu.sa
} 
antibiotic discovery since the "Golden era of antibiotic discovery" (1940-1960) 2 . Though some initial success was achieved during the late $60 \mathrm{~s}$ to mid-70s, by modification of the already available antibiotics ${ }^{4}$, by 1990 , it was clear that the spread of bacterial resistance to antibiotics had far greater pace than the induction of new antibiotics $^{2,4}$. Subsequently, over the past few decades, new technological platforms combining synthetic chemistry and genomics approach also failed to provide even a single agent in the industrial pipeline ${ }^{3,7}$. Thus, the depletion of the antibiotic arsenal and the continuous rise in resistance has led to the exploration of novel antibacterial therapeutics that are refractory to the development of antibiotic resistance mechanisms ${ }^{2-4}$.

Quorum sensing (QS), a global regulatory network, characterized in the majority of bacteria including drug resistant biofilm-forming pathogens, involves the production of extracellular small signaling molecules or auto-inducers (AIs). The subsequent detection of these molecules induces the expression of specific genes, as a function of increasing bacterial population density ${ }^{8,9}$. The expression of QS-controlled genes is involved in the production of virulence factors and plays a key role in bacterial pathogenesis ${ }^{10,11}$. Thus, the disruption of bacterial communication system offers an alternative and possibly safer strategy for effective control of bacterial infections. Targeting QS is advantageous over conventional anti-bacterial strategies, as the former treatment does not involve the suppression of bacterial growth and hence does not exert a selective pressure, which may lead to the development of resistance ${ }^{12,13}$.

In this context, the use of nanomaterials as potential quorum sensing inhibitors (QSIs) against nosocomial pathogens including Pseudomonas aeruginosa, is being explored by researchers ${ }^{14}$. Nanomaterials offer several remarkable features, such as large specific surface area, small size, excellent biocompatibility, and in limited concentrations, they are non-toxic and eco-friendly in nature. Among various semiconductor metal oxides, yttrium oxide nanoparticles have attracted growing interest owing to their excellent physiochemical properties ${ }^{15,16}$. They are transparent in the visible region, semiconductor in nature, have high refractive index, large gap band $(5.8 \mathrm{Ev})$, high specific surface area and volume, high photochemical stability and excellent biocompatibility at environmental conditions ${ }^{17,18}$. These novel features make them ideal candidates for use in the various biomedical applications ${ }^{19,20}$.

In the present study, we chemically synthesized and characterized the core and core/shell NSs. Scanning electron microscopic images and X-ray photoelectron spectroscopy were used to determine the size, shape, surface morphology and chemical composition of the prepared NSs. In a comparative study, we evaluated the efficacy of core and core/shell NSs against QS mediated virulence factors and biofilm formation in gram-negative pathogens. To the best of our knowledge, this is the first report to investigate the impact of yttrium oxide on the interference of QS and biofilm inhibition. These findings suggest that chemically synthesized metal oxide NSs could be exploited in medical settings as well in the food \& beverage industries for removal of microorganisms.

\section{Methods}

Sample preparation. $\mathrm{Y}\left(\mathrm{NO}_{3}\right)_{3} 6 \mathrm{H}_{2} \mathrm{O}\left(99 \%\right.$, BDH chemicals England), $\mathrm{Tb}\left(\mathrm{NO}_{3}\right)_{3} 6 \mathrm{H}_{2} \mathrm{O}(99 \%$, Alfa Aesar, Germany), $\mathrm{Si}\left(\mathrm{OC}_{2} \mathrm{H}_{5}\right)_{4}$ (TEOS, E-Merck, Germany), and $\mathrm{CH}_{4} \mathrm{~N}_{2} \mathrm{O}$ (Urea) were used directly as received. Milli-Q (Millipore, USA) $\mathrm{H}_{2} \mathrm{O}$ was used for preparation and characterization of the samples. All the analytical grade chemicals were used without further purification from the standard brand of E. Merck Limited, India.

Synthesis of $\mathrm{Y}_{2} \mathrm{O}_{3}: \mathrm{Tb}_{\mathrm{S}} \mathrm{SiO}_{2}$ core/shell nanospheres. Spherical shaped $\mathrm{Y}_{2} \mathrm{O}_{3}: \mathrm{Tb}$ NSs were prepared using methods described in previously published literature reports ${ }^{17,18}$. An equimolar aqueous solution of yttrium nitrate and terbium nitrate in the ratio of 95:05 was mixed with urea, under constant stirring on a hot plate, at room temperature. The resultant mixture was heated up to $100^{\circ} \mathrm{C}$ under reflux for $2 \mathrm{~h}$. The precipitate segregated at the bottom of the flask, which was separated by centrifugation, washed with distilled water, and dried overnight in an oven, at $60^{\circ} \mathrm{C}$. A silica layer was deposited by Stober sol-gel process ${ }^{18,21-23}$. Luminescent NSs $(100 \mathrm{mg})$ were dispersed in an aqueous solution by ultra-sonication for $30 \mathrm{~min}$. These NSs were then separated by centrifugation and further dispersed in an aqueous solution containing $80 \mathrm{~mL} \mathrm{C}_{2} \mathrm{H}_{5} \mathrm{OH}, 20 \mathrm{~mL} \mathrm{H}_{2} \mathrm{O}$, and $1 \mathrm{~mL} \mathrm{NH}_{4} \mathrm{OH}$, on a hot plate at ambient temperature. TEOS was introduced slowly into the vigorously stirred solution. The reaction proceeded for $5-6 \mathrm{~h}$ at ambient conditions. The precipitate obtained was isolated by centrifugation, washed with distilled water, and dried overnight in an oven at $60^{\circ} \mathrm{C}$.

\section{Characterization}

The morphology of the samples was studied using scanning electron microscope (SEM, JSM-7600F JEOL, Japan) energy dispersive X-ray analysis (EDX), operated at an accelerating voltage $5 \mathrm{kV}$. The chemical composition was determined using X-ray photoelectron spectroscopy (XPS) using ESCA model VG 3000 with monochromatic Mg $\mathrm{K} \alpha$ line $(1253.6 \mathrm{eV})$ radiation.

Bacterial strains and growth conditions. Chromobacterium violaceum 12472 is a wild-type, purple colored bacterium, which produces violacein in response to cognate acyl-homoserine lactone (AHL) molecules. C. violaceum $\mathrm{CVO} 26$ is a mutant strain that produces violacein in response to exogenous AHL molecules. QS regulated virulence functions are studied using pathogenic model bacteria $P$. aeruginosa $\mathrm{PAO}^{24}$. All strains were maintained on Luria Bertani or LB broth ( $15.0 \mathrm{~g}$ tryptone, $0.5 \%$ yeast extract, $0.5 \% \mathrm{NaCl}$ ) solidified with $1.5 \%$ agar (Hi-media). Strains of C. violaceum 12472, C. violaceum CVO26 and P. aeruginosa PAO1 were cultivated at $28^{\circ} \mathrm{C}$ and $37^{\circ} \mathrm{C}$ respectively.

Determination of minimum inhibitory concentration (MIC). Macrobroth dilution method of CLSI was used to determine the MICs of synthesized core and core/shell NSs against the test bacterial pathogens ${ }^{14}$. All assays were performed using concentrations below the MICs, i.e., $1 / 16 \times$ MIC-1/2 $\times$ MIC. 
Violacein inhibition assay. Overnight grown Chromobacterium violaceum $\mathrm{CV} 026\left(\mathrm{OD}_{600 \mathrm{~nm}}=0.1\right)$ was inoculated in Erlenmeyer flasks containing Luria broth (LB). LB supplemented with C6-HSL ( $10 \mu \mathrm{M} / \mathrm{L})$ and the core and core/shell NSs and incubated under shaking for $24 \mathrm{~h}^{25}$. Violacein production by Chromobacterium violaceum (CVO26) in presence of core-NSs and core/shell NSs was studied using the method described by Husain et al. ${ }^{25}$.

Effect on virulence factors production. LasB elastolytic activity assay. The elastolytic activity was determined as described ${ }^{26}$. Briefly, treated and untreated PAO1 was incubated for $16 \mathrm{~h}$ at $37^{\circ} \mathrm{C}$. Culture supernatant $(100 \mu \mathrm{L})$ was added to ECR buffer $(900 \mu \mathrm{L})$ and left at shaking for $3 \mathrm{~h}$ at $37^{\circ} \mathrm{C}$. Centrifugation was performed to remove insoluble ECR, and absorption was measured at $495 \mathrm{~nm}$.

Azocasein-degrading proteolytic activity. Proteolytic activity in cell-free supernatants of PAO1 was determined using the assay described by Kessler et al. ${ }^{27}$. Briefly, culture supernatants $(150 \mu \mathrm{L})$ from NSs treated and untreated cultures were added to $1 \mathrm{~mL}$ of $0.3 \%$ azocasein (Sigma, USA) and incubated at $37^{\circ} \mathrm{C}$ for $15 \mathrm{~min}$. Trichloroacetic acid was added to stop the reaction. Absorbance was read at $400 \mathrm{~nm}$.

Pyocyanin assay. Pyocyanin was measured by extracting $5 \mathrm{~mL}$ culture supernatant of PAO1 with $3 \mathrm{~mL}$ of chloroform and then re-extracted in $1 \mathrm{~mL}$ of $0.2 \mathrm{M} \mathrm{HCl}$, to get a pink to deep-red colored solution. The absorbance of the extracted solution was measured at $520 \mathrm{~nm}^{28}$.

Swarming motility assay. Swarming motility was determined by point inoculation overnight culture of $P$. aeruginosa (PAO1) at the center of the plate medium consisting of LB broth supplemented with $0.3 \%$ agar with or without various sub-inhibitory concentrations $(25-200 \mu \mathrm{g} / \mathrm{mL})$ of core and core/shell NSs ${ }^{29}$. Plates were incubated at $37^{\circ} \mathrm{C}$ for $24 \mathrm{~h}$ and diameter of swarm was measured.

Extraction and quantification of exopolysaccharide (EPS). EPS produced in treated and untreated PAO1 was extracted by centrifugation, and the resultant supernatant was filtered. EPS was precipitated by adding ethanol (100\%) to the supernatant and incubating at $4{ }^{\circ} \mathrm{C}^{30}$. Method described by Dubois et al. ${ }^{31}$ was used to quantify the EPS.

Assay for biofilm inhibition. Microtiter plate (MTP) assay was employed to assess the effect of the synthesized NSs on biofilm formed by PAO ${ }^{32}$. Briefly, cells with biofilms grown for $24 \mathrm{~h}$ in MTP were stained with crystal violet and quantified by measuring absorbance at $470 \mathrm{~nm}$.

Cell attachment assay. Core and core/shell NSs $(100 \mu \mathrm{L})$ were added to 96 -well microtiter plates, and culture $(100 \mu \mathrm{L})$ was added into each well. The MTPs were incubated at $37^{\circ} \mathrm{C}$ for $8 \mathrm{~h}$ without shaking to allow cell attachment and biofilm development. Following incubation, the modified crystal violet assay was performed to assess biofilm biomass ${ }^{33}$.

Analysis of lasB and pqsA transcriptional activity in E. coli. The effect of NSs on the lasB and pqsA transcriptional activity in reporter strains, E. coli MG4/pKDT17 and E. coli pEAL08-2 was measured using the $\beta$-galactosidase assay ${ }^{32,33}$. Briefly, quorum-sensing signal molecules (AHLs) from overnight grown PAO1 culture supernatant were extracted with ethyl acetate. Subsequently, $2 \mathrm{~mL}$ of reporter strains and $0.5 \mathrm{~mL}$ of the extracted supernatant were incubated in a rotatory water bath for $5 \mathrm{~h}$ at $30^{\circ} \mathrm{C}$. Further, the mixture was centrifuged, resultant pellet was resuspended in $\mathrm{Z}$ buffer $\left(\mathrm{Na}_{2} \mathrm{HPO}_{4} .7 \mathrm{H}_{2} \mathrm{O}, 0.06 \mathrm{M} ; \mathrm{NaH}_{2} \mathrm{PO}_{4} \cdot \mathrm{H}_{2} \mathrm{O}, 0.04 \mathrm{M} ; \mathrm{KCl}, 0.01 \mathrm{M}\right.$; $\mathrm{MgSO}_{4} .7 \mathrm{H}_{2} \mathrm{O}, 0.001 \mathrm{M} ; \beta$-mercaptoethanol, $\left.0.05 \mathrm{M} ; \mathrm{pH} 7.0\right)$. Chloroform $(200 \mu \mathrm{L})$ and $0.1 \%$ sodium dodecyl sulfate $(100 \mu \mathrm{L})$ were added to lyse the cells, and $0.4 \mathrm{~mL}$ of $\mathrm{O}$-nitrophenol- $\beta$-D-galactopyranoside was also added. Upon appearance of yellow color, the reaction was stopped by addition of $1 \mathrm{~mL}$ of $1 \mathrm{M} \mathrm{Na}_{2} \mathrm{CO}_{3}$. Absorbance was read at 420 and $550 \mathrm{~nm}$. Units of $\beta$-galactosidase were calculated as $1000 \times \mathrm{OD}_{420} \mathrm{~nm}-\left(1.75 \times \mathrm{OD}_{550 \mathrm{~nm}}\right) /$ time $\times$ volume $\times \mathrm{OD}_{600 \mathrm{~nm}}$.

Statistical analysis. All experiments were performed in triplicates and data obtained from the experiments were presented as mean values. The differences between control and test were analyzed using Student's $t$ test.

\section{Results and Discussion}

Morphological characterization. Scanning electron microscopy was performed to analyze the morphology of the prepared samples. Figure $1(\mathrm{a}-\mathrm{c})$ demonstrates that the formed core/shell particles were well separated, spherical shaped, uniform, with a rough surface, narrow size distribution, and average grain size of $110-130 \mathrm{~nm}$. SEM micrographs displayed that the particles are interconnected to each other because of the hydrophilic surface. This was expected owing to the grafting of silica layer over the surface of yttrium oxide NSs. The surface was covered with abundant silanol ( $\mathrm{Si}-\mathrm{OH}$ ) groups, which easily form a colloidal solution in aqueous media by hydrogen bonding. Due to the presence of hydrogen bonding, they were connected to each other and slightly aggregated. Energy dispersive X-ray analysis was used to monitor the chemical composition of the designed core/shell NSs (Fig. 1d). Figure 1d, shows all elements in the spectrum, including silica (Si), oxygen (O), yttrium (Y), and terbium $(\mathrm{Tb})$, which correspond to the core/shell NSs. This verified the core/shell nanostructure of the sample.

XPS analysis was carried out to examine the surface chemistry and existence of the $\mathrm{Y}_{2} \mathrm{O}_{3}$ : $\mathrm{Tb} @ \mathrm{SiO}_{2}$ core/shell nanostructures. The binding energy signals for $\mathrm{Y}\left(3 \mathrm{~d}_{5 / 2} .164 .2 \mathrm{eV}\right), \mathrm{O}(1 \mathrm{~s}, 532.0 \mathrm{eV}), \mathrm{Tb}\left(4 \mathrm{~d}_{5 / 2}, 155.7 \mathrm{eV}\right)$, and $\mathrm{Si}$ $\left(2 \mathrm{p}_{3 / 2}, 104.5 \mathrm{eV}\right)$, can be seen in Fig. $2(\mathrm{a}-\mathrm{d})^{34-39}$. In accordance with the SEM and EDX observations and literature 

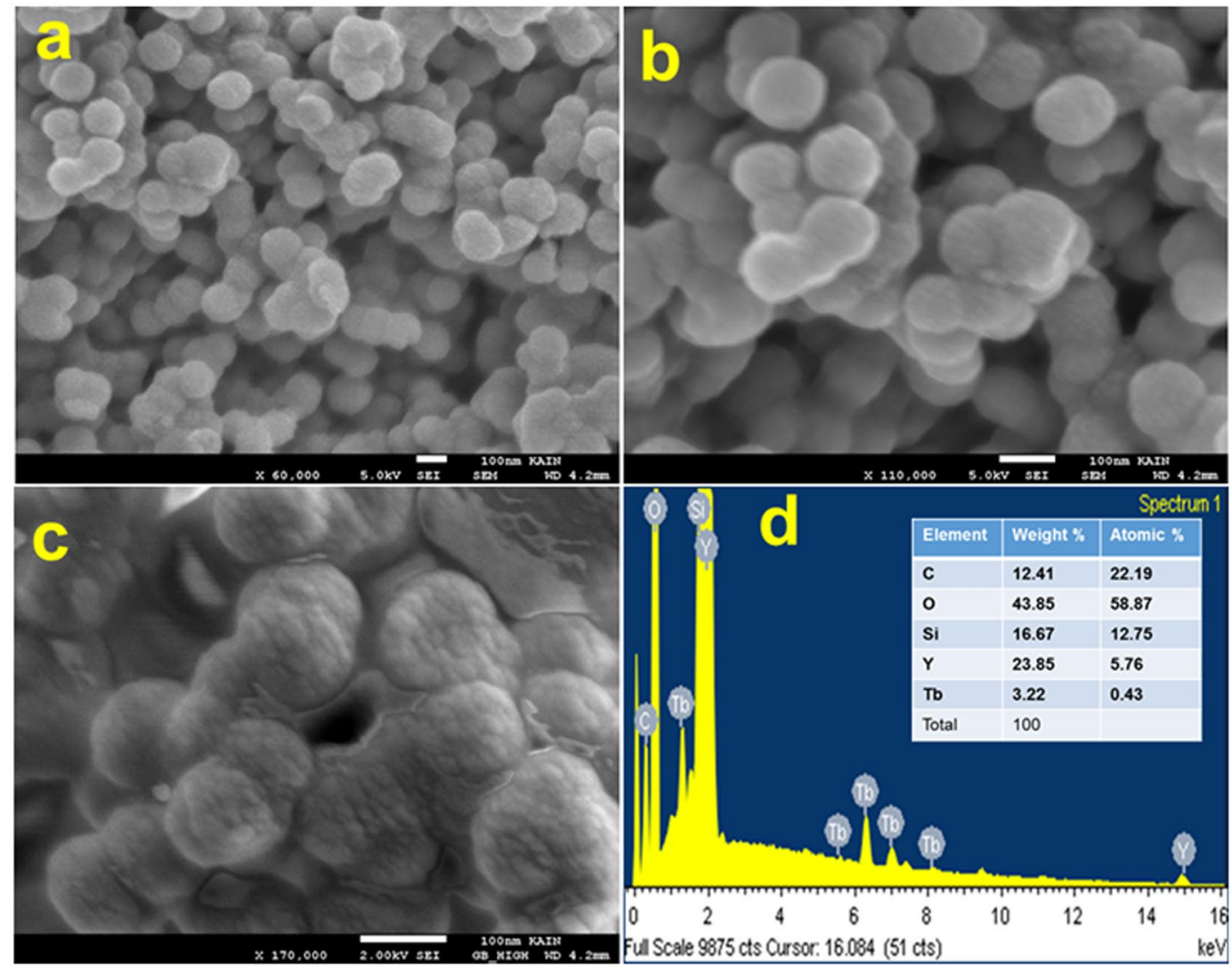

Figure 1. (a) Low magnification SEM image (b,c) high magnification SEM image and (d) EDX analysis of core/ shell NSs.

reports $^{34,35}$, these results inferred that the observed signals arose from the core/shell nanostructures. This provided additional evidence to confirm the successful development of core/shell nanostructures.

Minimum inhibitory concentration (MIC). The MIC of core-NSs and core/shell NSs was tested against all test pathogens. The MICs $(\mu \mathrm{g} / \mathrm{mL})$ of core-NSs were found to be 512, 512 and 1024 against CV12472, CVO26, and PAO1, respectively. Similarly, the MIC of core/shell NSs against all three test bacteria was $256 \mu \mathrm{g} / \mathrm{mL}$. Sub-MICs were used to assess the QS and biofilm inhibitory potential of the NSs. Our finding is in accordance with those reported against pathogenic bacteria using various nanomaterials $\mathrm{s}^{40-44}$.

Anti-QS assay (violacein inhibition). Potential quorum sensing inhibitory potential of the synthesized NSs was screened using the biosensor strain Chromobacterium violaceum CV12472. Production of a violet-colored pigment called violacein in this strain is regulated by CviIR-dependent quorum sensing system. Therefore, pigment inhibition is indicative of interference with AHL-regulated QS ${ }^{45}$. Violacein levels were quantified by extracting violacein from biosensor strain Chromobacterium violaceum CVO26 at sub-MICs of NSs. Colorimetric analysis revealed a substantial drop in violacein production by CVO26 at all tested concentrations of NSs. Core-NSs at sub-MICs of 25,50, 100 and $200 \mu \mathrm{g} / \mathrm{mL}$ demonstrated $18 \%, 43 \%, 56 \%$ and $75 \%$ reduction in violacein, respectively (Fig. 3a). Similarly, core/shell NSs also interfered with AHL-regulated violacein production in a concentration-dependent manner and $38-84 \%$ reduction was recorded (Fig. 3a). The effect of the core-NSs and core/shell NSs $(200 \mu \mathrm{g} / \mathrm{mL})$ on the growth of CVO26 was also examined and no significant difference in cell density was recorded (Fig. 3b). These findings demonstrate that the inhibition of violacein by NSs in CVO26 is growth independent i.e. the growth is not affected. Thus, it is anticipated that the NSs (core \& core/shell NS) interfere with AHL-regulated QS signaling. Our findings are validated by reports on anti-QS properties of NSs. Silver nanowires demonstrated $80 \%$ decrease in violacein production in CVO26 at $4 \mathrm{mg} / \mathrm{mL}$ concentration ${ }^{46}$, while Singh et al. ${ }^{47}$ demonstrated $100 \%$ pigment inhibition with biogenic silver NSs.

Inhibition of QS-regulated virulence factors by core and core/shell NSs. Growth kinetics studies of PAO1 revealed no significant change in cell density after treatment with $200 \mu \mathrm{g} / \mathrm{mL}$ concentration of core and core/shell NSs as compared to untreated control (Fig. 4a). Thus, the synthesized NSs do not inhibit the growth of the pathogen. The effect of sub-MIC of synthesized core and core/shell NSs on various QS-regulated virulence functions in PAO1 was also assessed. Core-NSs demonstrated the reduction of all virulence factors in a concentration-dependent manner $(25-200 \mu \mathrm{g} / \mathrm{mL})$ : elastase $(18-57 \%)$, total protease (21-61\%), pyocyanin (06-55\%) (Fig. 4b). Core/shell NS was found to be more potent in inhibiting the studied virulence factors over 

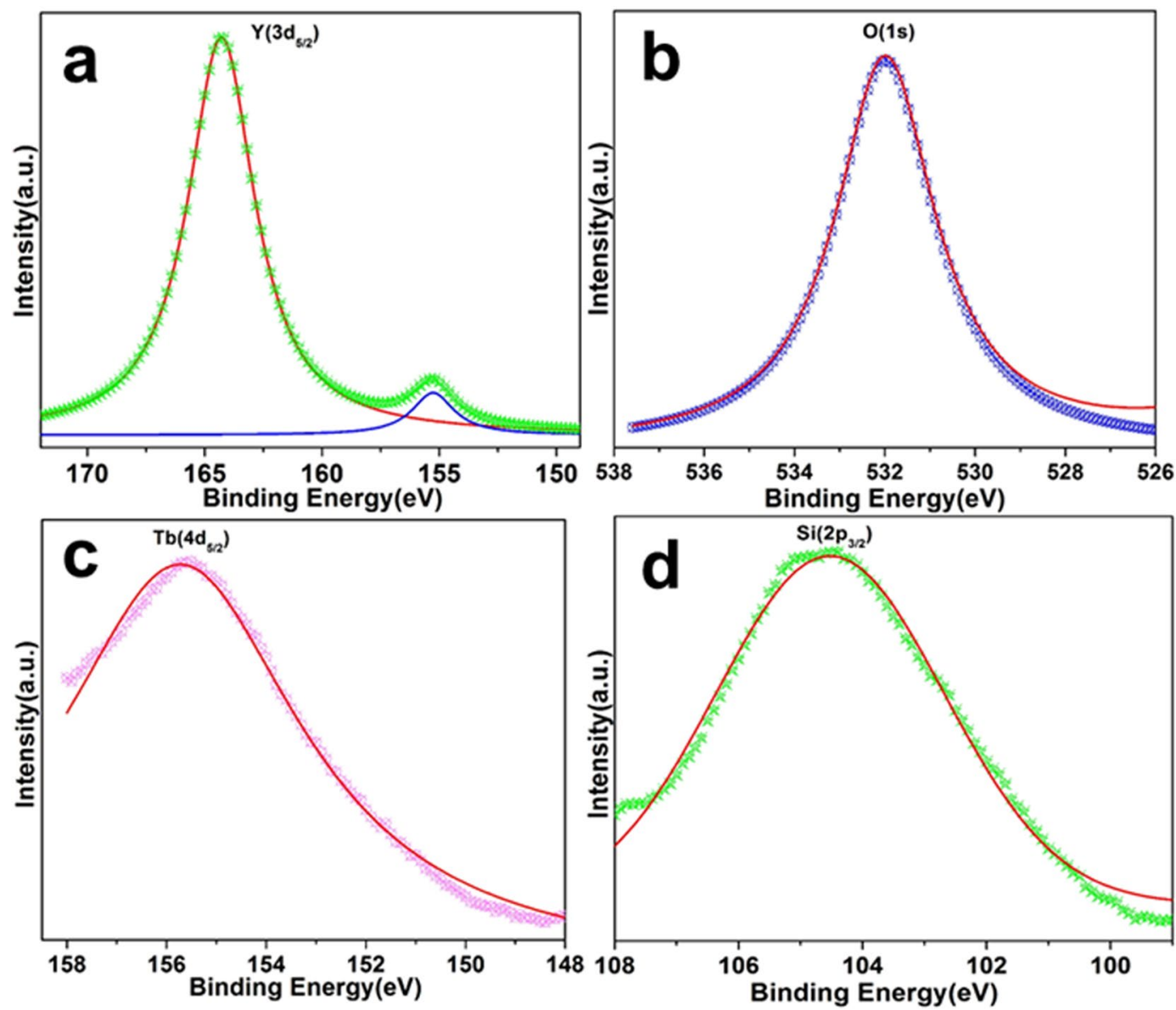

Figure 2. XPS analysis $(\mathbf{a}) \mathrm{Y}\left(3 \mathrm{~d}_{5 / 2}\right)(\mathbf{b}) \mathrm{O}(1 \mathrm{~s})(\mathbf{c}) \mathrm{Tb}\left(4 \mathrm{~d}_{5 / 2}\right)$ and (d) $\mathrm{Si}\left(2 \mathrm{p}_{3 / 2}\right)$ signals of core/shell NSs.
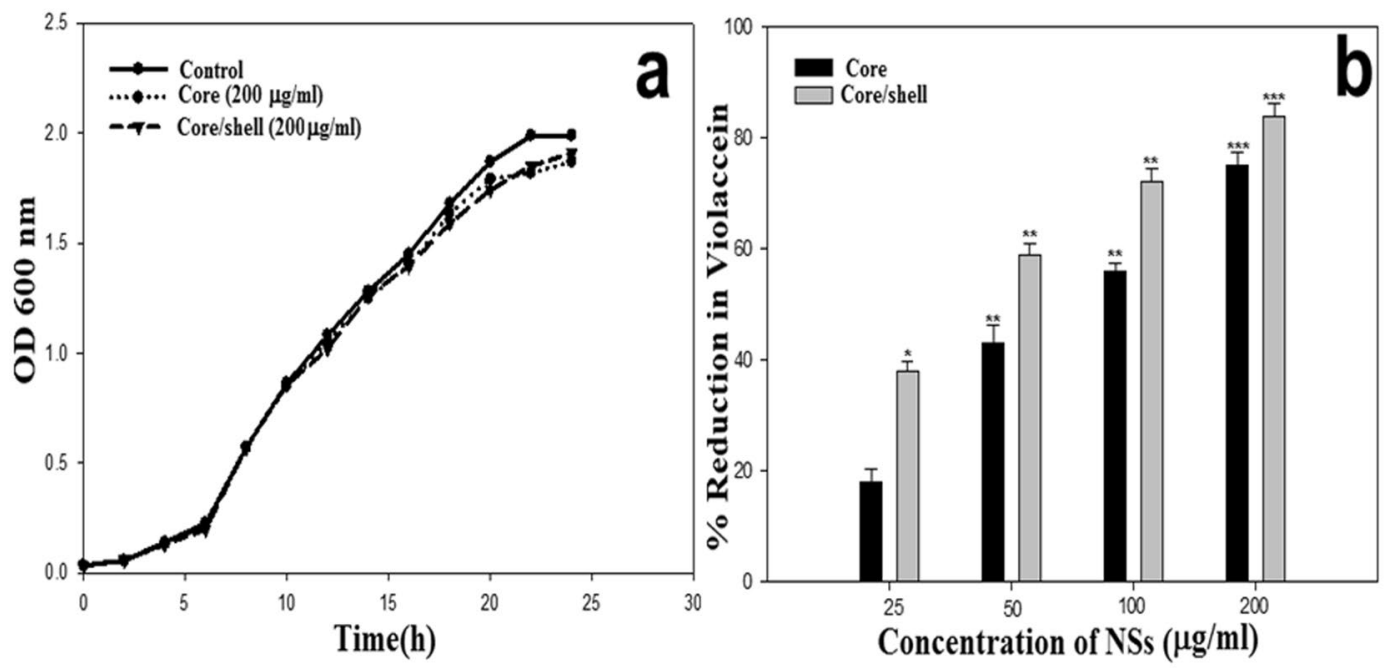

Figure 3. Assay for QS inhibition. (a) Inhibition of violacein production in CVO26 by core and core/shell NSs concentrations $(25,50,100$, and $200 \mu \mathrm{g} / \mathrm{mL}$ ) was quantified spectrophotmetrically (OD at $585 \mathrm{~nm}$ ). (b) Growth curve analysis of CVO26 at $200 \mu \mathrm{g} / \mathrm{mL}$ concentration of NSs.

the same concentration range. The core/shell NS treated PAO1 cells displayed substantially reduced azocasein degrading protease activity (84\%), elastase activity $(81 \%)$, and pyocyanin production $(89 \%)$ at $200 \mu \mathrm{g} / \mathrm{mL}$ concentration as compared to untreated control (Fig. 4c). 

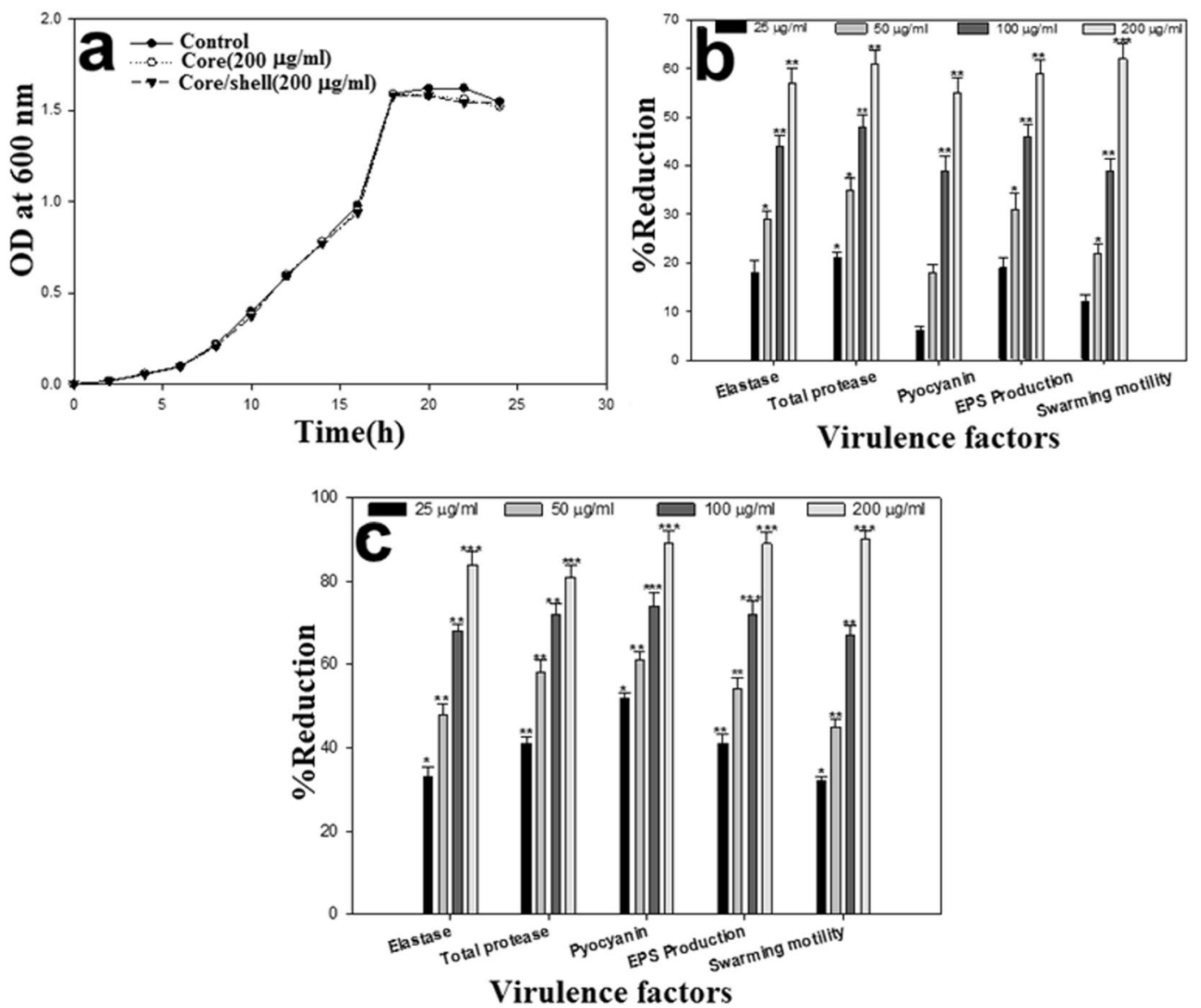

Figure 4. Effect on QS regulated virulence traits of PAO1. (a) Growth curve analysis of PAO1 at $200 \mu \mathrm{g} / \mathrm{mL}$ concentration of NSs. (b) Effect of sub-MICs of TYO on inhibition of quorum sensing regulated virulence factors. (c) Effect of sub-MICs of TYSO on inhibition of quorum sensing regulated virulence factors. Data is presented as mean percent reduction \pm SD. *Significance at $\mathrm{p} \leq 0.05,{ }^{* *}$ significance at $\mathrm{p} \leq 0.005,{ }^{* * *}$ Significance at $\mathrm{p} \leq 0.001$.

Protease and elastase enzymes play a major role in the pathogenesis of $P$. aeruginosa, as they are responsible for host tissue degradation. Production of pyocyanin in P. aeruginosa is also QS-regulated and this secondary metabolite along with its precursor causes severe toxic effects. In the present study, the production of these virulence traits was reduced significantly at sub-MICs. These findings also support our previous observations on $\mathrm{ZnO}$ nanoparticles that reduced the production of elastase and pyocyanin in clinical strains of $P$. aeruginos $a^{48}$. The effect of synthesized NSs on swarming motility and EPS production by PAO1 was also examined. The addition of sub-inhibitory concentrations $(25-200 \mu \mathrm{g} / \mathrm{mL})$ of core-NSs and core/shell NSs demonstrated a statistically significant reduction of swarming motility and EPS production. The reduction in swarming motility by core-NSs ranged from $12-62 \%$ while EPS production decreased by $19-59 \%$ over untreated control (Fig. $4 \mathrm{~b}$ ). The core/ shell NSs demonstrated a significant reduction in swarming migration and EPS at all tested concentrations. The motility of PAO1 was reduced by $32-90 \%$ and EPS production was impaired by $41-89 \%$ (Fig. $4 \mathrm{c}$ ). These findings are significant as these two virulence traits play an important part in biofilm formation by P. aeruginosa. Motility and EPS are responsible for the successful attachment, development, and maturation of biofilm. Interference with either of the two leads to impaired biofilm formation thereby reducing the resistance of sessile cells to drugs and host immune system. Singh et al. ${ }^{47}$ demonstrated reduced migration diameter of PAO1 upon treatment with $25 \mu \mathrm{g} / \mathrm{mL}$ of biogenic silver NSs. This was probably the first report on NS targeting motility and EPS production in PAO1.

Effect on $\beta$-galactosidase activity. The effect of $25-200 \mu \mathrm{g} / \mathrm{mL}$ concentration of core and core/shell NSs on lasB and $p q s A$ transcriptional activity was examined using $\beta$-galactosidase assay. Core and core/shell NSs reduced the las $B$ transcriptional activity by $41 \%$ and $65 \%$ respectively. Moreover, $55 \%$ and $67 \%$ downregulation in $p q s A$ was also recorded at $200 \mu \mathrm{g} / \mathrm{mL}$ concentration of core and core $/$ shell NSs (Table 1 ). Pearson et al. ${ }^{49}$ reported a positive correlation between AHL concentration and lasB-lacZ expression. Our findings correlate well with the above observations, as reduced $\beta$-galactosidase activity is indicative of reduced AHL levels and, therefore, reduced expression of the lasB gene. Similarly, core and core/shell NSs reduce the transcriptional activation of $p q s A$ and inhibit the $p q s$ system that controls the production of virulence factors like pyocyanin. These results 


\begin{tabular}{|l|l|l|l|l|}
\hline \multirow{2}{*}{$\begin{array}{l}\text { Concentration } \\
(\boldsymbol{\mu} / \mathrm{mL})\end{array}$} & Core-NSs & Core/shell NSs \\
\cline { 2 - 5 } & lasR & pqsA & lasR & pqsA \\
\hline Control & $943 \pm 34.6$ & $1042 \pm 23.4$ & $943 \pm 34.6$ & $1042 \pm 23.4$ \\
\hline 25 & $859 \pm 21.2$ & $881 \pm 36.8$ & $799 \pm 24.4$ & $724 \pm 31.9$ \\
\hline 50 & $714 \pm 28.8$ & $635 \pm 27.9^{*}$ & $680 \pm 38.8$ & $503 \pm 43.3^{*}$ \\
\hline 100 & $601 \pm 42.1^{*}$ & $517 \pm 38.2^{*}$ & $536 \pm 34.6^{*}$ & $389 \pm 48.1^{* *}$ \\
\hline 200 & $556 \pm 34.7^{*}$ & $365 \pm 37.1^{* *}$ & $424 \pm 44.3^{* *}$ & $344 \pm 31.9^{* *}$ \\
\hline
\end{tabular}

Table 1. Effect of Core and Core/shell NSs on transcriptional activity of lasR and pqsA. Transcriptional activity was measured via $\beta$-galactosidase activity of the lacZ gene fusion products and expressed as Miller Units.

*Indicates significance at $p<0.05$. **Indicates significance at $p<0.005$.
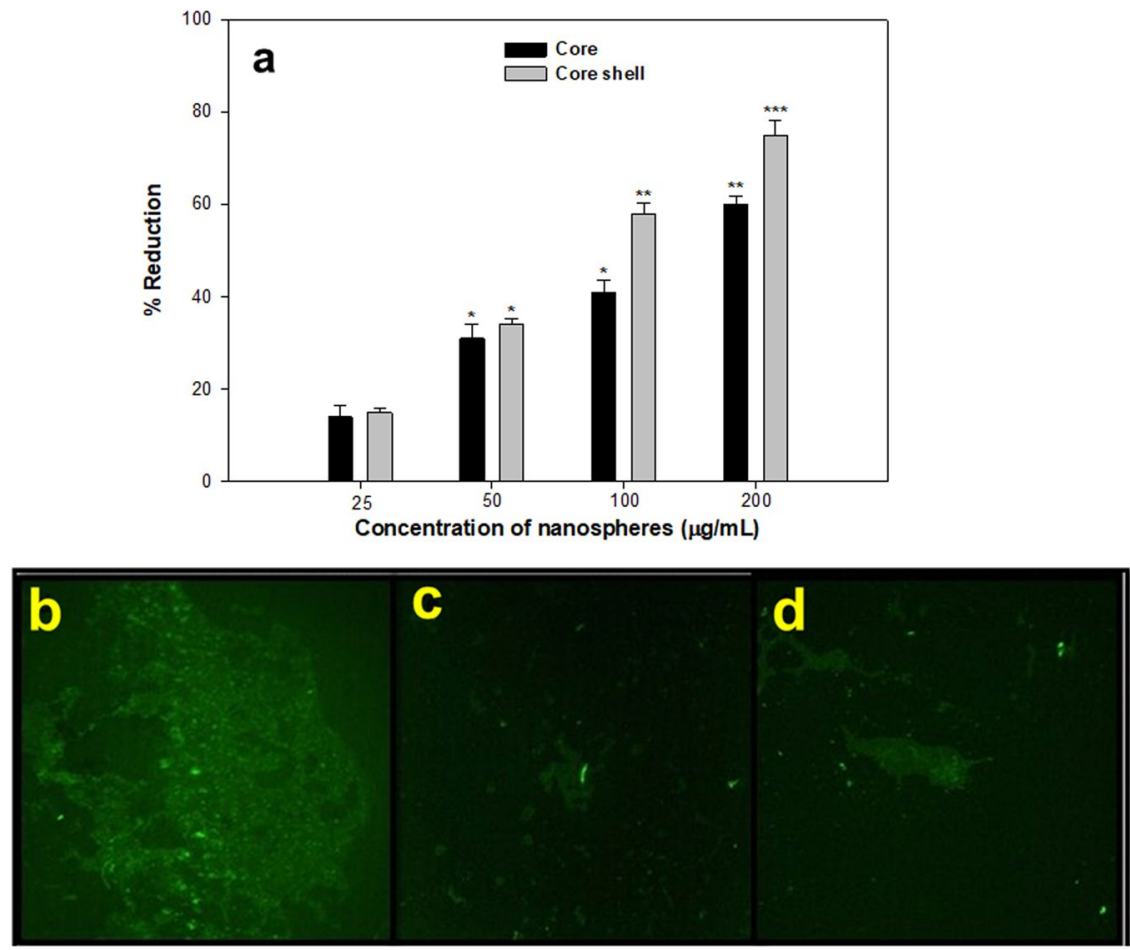

Figure 5. Anti-biofilm activity of NSs. (a) Percent inhibition of biofilm formation of PAO1 by sub-MICs of core and core/shell NSs using microtitre plate assay. (b) Images of $(\mathbf{a}-\mathbf{c}) \mathrm{CV}$-staining light microscope, (d-f) acridine orange staining CLSM. (a,d) untreated control; (b,e) $200 \mu \mathrm{g} / \mathrm{mL}$ core and (c,f) $200 \mu \mathrm{g} / \mathrm{mL}$ core/shell NSs.

indicate that the synthesized core and core/shell NSs have broad-spectrum anti-QS activity and are active against both las and pqs system of $P$. aeruginosa.

Inhibition of biofilm formation. Biofilm inhibition by core-NSs and core/shell NSs was tested using microtiter plate assay. Biofilm formation was reduced by $14-60 \%$ by core-NSs in a concentration-dependent manner (Fig. 5a). Core/shell NSs were more effective in inhibiting biofilm at higher tested concentrations as compared to core-NSs. At 25, 50, 100 and $200 \mu \mathrm{g} / \mathrm{mL}$ concentrations, core/shell NSs impaired the biofilm formation by $15 \%$, $34 \%, 58 \%$, and $75 \%$ over untreated control (Fig. 5a). CLSM images confirmed the results of light microscopy displaying major disruption in the architecture of biofilms of PAO1 (Fig. 5b-d). A biofilm is a complex congregation of micro-colonies that is resistant to drugs and plays a key role in the pathogenesis of opportunistic bacteria such as $P$. aeruginos $a^{50}$. Biofilms are therefore interesting drug targets in fight against drug resistance and persistent infections. We recorded a significant reduction in biofilm biomass upon treatment with the core and Core/shell NSs. Our study is in accordance with previous reports that showed the reduction of biofilms in P. aeruginosa PAO1 by nanoparticles of zinc oxide ${ }^{14,51}$, tin oxide ${ }^{52}$ and iron oxides ${ }^{53}$, silica nanoparticles ${ }^{54}$ antimicrobials like doxycycline and ceftazidime $e^{29,55}$.

Effect on cell attachment. Cell attachment is the first step in biofilm formation and it has been established by previous reports that inhibition of cell attachment to a substrate is easier to achieve than inhibition of the growth of an already established biofilm ${ }^{56}$. Therefore, NSs were examined for anti-attachment property against PAO1. The synthesized core-NSs showed significant inhibition of cell attachment to the microtiter plate. Core and 


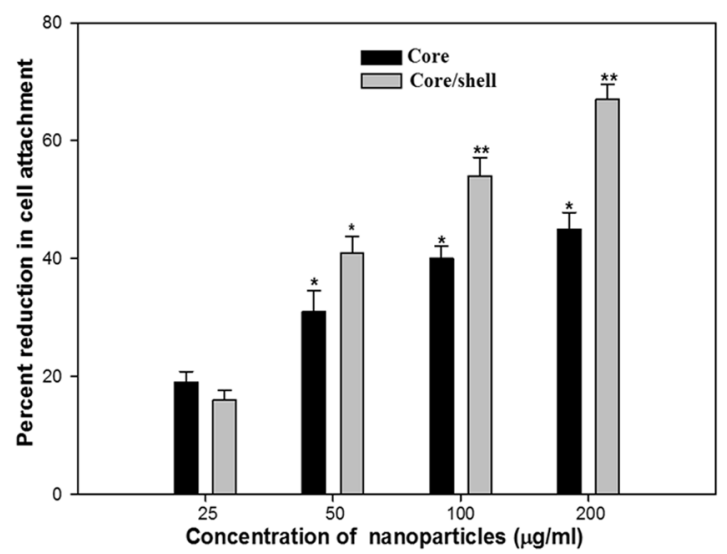

Figure 6. The effect of sub-MICs of synthesized core and core/shell NSs on the attachment of PAO1, expressed as percentage inhibition.

core/shell NSs showed maximum activity of $45 \%$ and $67 \%$ at $200 \mu \mathrm{g} / \mathrm{mL}$ concentrations, respectively. Core-NSs at concentrations 25,50 , and $100 \mu \mathrm{g} / \mathrm{mL}$ showed $19 \%, 31 \%$, and $40 \%$ inhibition of cell attachment over control. Similarly, $16 \%, 41 \%$, and $54 \%$ inhibition was recorded at lower tested concentrations $(25,50,100 \mu \mathrm{g} / \mathrm{mL})$, respectively (Fig. 6). These results indicate that the synthesized core/shell NSs inhibit cell attachment and hence prevent biofilm formation. These core/shell NSs may be used as a coating on surfaces to prevent biofilm formation.

\section{Conclusion}

To conclude, spherical shaped monodispersed core and core/shell NSs were successfully produced by homogeneous urea-based co-precipitation process. The morphology, size, and elemental composition of the samples were characterized by scanning electron microscopy, EDX, and XPS analysis. The present findings highlight the QS and biofilm inhibitory potential of chemically synthesized NSs (Core and Core/shell NSs), which may be exploited to treat drug-resistant infections of $P$. aeruginosa in future. The anti-biofilm activity results clearly indicate that core and core/shell NSs may be helpful in preventing and fighting drug-resistant infections.

Received: 21 May 2019; Accepted: 28 October 2019;

Published online: 06 December 2019

\section{References}

1. Levy, S. B. \& Marshall, B. Antibacterial resistance worldwide: causes, challenges and responses. Nat Med 10, S122-S129, https://doi. org/10.1038/nm1145(2004).

2. Katz, M. L., Mueller, L. V., Polyakov, M. \& Weinstock, S. F. Where have all the antibiotic patents gone? Nat Biotechnol 24, 1529-1531, https://doi.org/10.1038/nbt1206-1529(2006).

3. Brussow, H. Infection therapy: the problem of drug resistance - and possible solutions. Microb Biotechnol 10, 1041-1046, https://doi. org/10.1111/1751-7915.12777 (2017).

4. Fischbach, M. A. \& Walsh, C. T. Antibiotics for Emerging Pathogens. Science 325, 1089-1093, https://doi.org/10.1126/ science.1176667 (2009).

5. Boucher, H. W. et al. Bad Bugs, No Drugs: No ESKAPE! An Update from the Infectious Diseases Society of America. Clin Infect Dis 48, 1-12, https://doi.org/10.1086/595011 (2009).

6. Higgins, J. P. T., Thompson, S. G. \& Spiegelhalter, D. J. A re-evaluation of random-effects meta-analysis. J R Stat Soc a Stat 172, 137-159, https://doi.org/10.1111/j.1467-985X.2008.00552.x (2009).

7. Payne, J. D. et al. The role of sleep in false memory formation. Neurobiol Learn Mem 92, 327-334, https://doi.org/10.1016/j. nlm.2009.03.007 (2009).

8. Miller, M. B. \& Bassler, B. L. Quorum sensing in bacteria. Annu Rev Microbiol 55, 165-199, https://doi.org/10.1146/annurev. micro.55.1.165 (2001).

9. Waters, C. M. \& Bassler, B. L. Quorum sensing: Cell-to-cell communication in bacteria. Annu Rev Cell Dev Bi 21, 319-346, https:// doi.org/10.1146/annurev.cellbio.21.012704.131001 (2005).

10. Antunes, L. C., Levandovski, R., Dantas, G., Caumo, W. \& Hidalgo, M. P. Obesity and shift work: chronobiological aspects. Nutr Res Rev 23, 155-168, https://doi.org/10.1017/S0954422410000016 (2010).

11. Rutherford, S. T. \& Bassler, B. L. Bacterial Quorum Sensing: Its Role in Virulence and Possibilities for Its Control. Csh Perspect Med 2, https://doi.org/10.1101/cshperspect.a012427 (2012).

12. Rasko, D. A. \& Sperandio, V. Anti-virulence strategies to combat bacteria-mediated disease. Nat Rev Drug Discov 9, 117-128, https:// doi.org/10.1038/nrd3013 (2010).

13. LaSarre, B. \& Federle, M. J. Exploiting Quorum Sensing To Confuse Bacterial Pathogens. Microbiol Mol Biol R 77, 73-111, https:// doi.org/10.1128/Mmbr.00046-12 (2013).

14. Al-Shabib, N. A. et al. Biogenic synthesis of Zinc oxide nanostructures from Nigella sativa seed: Prospective role as food packaging material inhibiting broad-spectrum quorum sensing and biofilm (vol 6, 36761, 2016). Sci Rep-Uk 7, https://doi.org/10.1038/ srep42266 (2016).

15. Nalini, T., Basha, S. K., Sadiq, A. M. M., Kumari, V. S. \& Kaviyarasu, K. Development and characterization of alginate/chitosan nanoparticulate system for hydrophobic drug encapsulation. J Drug Deliv Sci Tec 52, 65-72, https://doi.org/10.1016/j. jddst.2019.04.002 (2019).

16. Rathnakumar, S. S. et al. Stalling behaviour of chloride ions: A non-enzymatic electrochemical detection of alpha-Endosulfan using CuO interface. Sensor Actuat B-Chem 293, 100-106, https://doi.org/10.1016/j.snb.2019.04.141 (2019). 
17. Ansari, A. A., Ahmad, N., Labis, J. P., El-Toni, A. M. \& Khan, A. Aqueous dispersible green luminescent yttrium oxide:terbium microspheres with nanosilica shell coating. Spectrochimica Acta Part A: Molecular and Biomolecular Spectroscopy, https://doi. org/10.1016/j.saa.2018.12.015 (2018).

18. Ansari, A. A. et al. Mesoporous multi-silica layer-coated $\mathrm{Y} 2 \mathrm{O} 3: \mathrm{Eu}$ core-shell nanoparticles: Synthesis, luminescent properties and cytotoxicity evaluation. Materials Science and Engineering: C 96, 365-373, https://doi.org/10.1016/j.msec.2018.11.046 (2019).

19. Lv, R. C. et al. Hollow Structured Y2O3:Yb/Er-CuxS Nanospheres with Controllable Size for Simultaneous Chemo/Photothermal Therapy and Bioimaging. Chemistry of Materials 27, 483-496, https://doi.org/10.1021/cm503647k (2015).

20. Liu, Z. et al. Long-circulating Er3+-doped $\mathrm{Yb} 2 \mathrm{O} 3$ up-conversion nanoparticle as an in vivo $\mathrm{X}$-Ray CT imaging contrast agent. Biomaterials 33, 6748-6757, https://doi.org/10.1016/j.biomaterials.2012.06.033 (2012).

21. Ansari, A. A. et al. Luminescent mesoporous LaVO4:Eu3 + core-shell nanoparticles: synthesis, characterization, biocompatibility and their cytotoxicity. Journal of Materials Chemistry 21, 19310-19316, https://doi.org/10.1039/cljm12871j (2011).

22. Ansari, A. A., Labis, J. P. \& Manthrammel, M. A. Designing of luminescent GdPO4:Eu@LaPO4@SiO 2 core/shell nanorods: Synthesis, structural and luminescence properties. Solid State Sciences 71, 117-122, https://doi.org/10.1016/j. solidstatesciences.2017.07.012 (2017).

23. Ansari, A. A., Parchur, A. K., Alam, M., Labis, J. \& Azzeer, A. Influence of Surface Coating on Structural and Photoluminescent Properties of CaMoO4:Pr Nanoparticles. Journal of Fluorescence 24, 1253-1262, https://doi.org/10.1007/s10895-014-1409-9 (2014).

24. McLean, R. J. C., Pierson, L. S. \& Fuqua, C. A simple screening protocol for the identification of quorum signal antagonists. J Microbiol Meth 58, 351-360, https://doi.org/10.1016/j.mimet.2004.04.016 (2004).

25. Husain, F. M. et al. Sub-MICs of Mentha piperita essential oil and menthol inhibits AHL mediated quorum sensing and biofilm of Gram-negative bacteria. Front Microbiol 6, https://doi.org/10.3389/fmicb.2015.00420 (2015).

26. Adonizio, A., Kong, K. F. \& Mathee, K. Inhibition of quorum sensing-controlled virulence factor production in Pseudomonas aeruginosa by south Florida plant extracts. Antimicrob Agents Ch 52, 198-203, https://doi.org/10.1128/Aac.00612-07 (2008).

27. Kessler, E., Safrin, M., Olson, J. C. \& Ohman, D. E. Secreted Lasa of Pseudomonas-Aeruginosa Is a Staphylolytic Protease. J Biol Chem 268, 7503-7508 (1993).

28. Essar, D. W., Eberly, L., Hadero, A. \& Crawford, I. P. Identification and characterization of genes for a second anthranilate synthase in Pseudomonas aeruginosa: interchangeability of the two anthranilate synthases and evolutionary implications. J Bacteriol 172, $884-900(1990)$

29. Husain, F. M. \& Ahmad, I. Doxycycline interferes with quorum sensing-mediated virulence factors and biofilm formation in gramnegative bacteria. World J Microbiol Biotechnol 29, 949-957, https://doi.org/10.1007/s11274-013-1252-1 (2013).

30. Huston, A. L., Methe, B. \& Deming, J. W. Purification, characterization, and sequencing of an extracellular cold-active aminopeptidase produced by marine psychrophile Colwellia psychrerythraea strain 34H. Appl Environ Microbiol 70, 3321-3328, https://doi.org/10.1128/AEM.70.6.3321-3328.2004 (2004).

31. Dubois, M., Gilles, K., Hamilton, J. K., Rebers, P. A. \& Smith, F. A colorimetric method for the determination of sugars. Nature 168, 167 (1951).

32. O’Toole, G. A. \& Kolter, R. Initiation of biofilm formation in Pseudomonas fluorescens WCS365 proceeds via multiple, convergent signalling pathways: a genetic analysis. Mol Microbiol 28, 449-461, https://doi.org/10.1046/j.1365-2958.1998.00797.x (1998).

33. Sandasi, M., Leonard, C. M. \& Viljoen, A. M. The in vitro antibiofilm activity of selected culinary herbs and medicinal plants against Listeria monocytogenes. Lett Appl Microbiol 50, 30-35, https://doi.org/10.1111/j.1472-765X.2009.02747.x (2010).

34. Yang, P. P. et al. MCM-41 functionalized with YVO4: Eu3+: a novel drug delivery system. Nanotechnology 18, https://doi. org/10.1088/0957-4484/18/23/235703 (2007).

35. Yu, M., Lin, J. \& Fang, J. Silica spheres coated with YVO4: Eu3+ layers via sol-gel process: A simple method to obtain spherical coreshell phosphors. Chemistry of Materials 17, 1783-1791, https://doi.org/10.1021/cm0479537 (2005).

36. Jafer, R. M. et al. X-ray photoelectron spectroscopy and luminescent properties of Y2O3:Bi3 + phosphor. Appl SurfSci 332, 198-204, https://doi.org/10.1016/j.apsusc.2015.01.009 (2015).

37. Qian, H. S. \& Zhang, Y. Synthesis of Hexagonal-Phase Core-Shell NaYF4 Nanocrystals with Tunable Upconversion Fluorescence. Langmuir 24, 12123-12125, https://doi.org/10.1021/la802343f (2008)

38. Kang, X. J. et al. Core-Shell Structured Up-Conversion Luminescent and Mesoporous NaYF4:Yb3+/Er3+@nSiO(2)@mSiO(2) Nanospheres as Carriers for Drug Delivery. Journal of Physical Chemistry C 115, 15801-15811, https://doi.org/10.1021/jp203039t (2011).

39. Wang, M. et al. Immunoassay of Goat Antihuman Immunoglobulin G Antibody Based on Luminescence Resonance Energy Transfer between Near-Infrared Responsive NaYF4:Yb, Er Upconversion Fluorescent Nanoparticles and Gold Nanoparticles. Analytical Chemistry 81, 8783-8789, https://doi.org/10.1021/ac901808q (2009).

40. Kaninnozhi, K., Basha, S. K., Kaviyarasu, K. \& SuganthaKumari, V. Salt Leaching Synthesis, Characterization and In Vitro Cytocompatibility of Chitosan/Poly(vinyl alcohol)/Methylcellulose - ZnO Nanocomposites Scaffolds Using L929 Fibroblast Cells. J Nanosci Nanotechno 19, 4447-4457, https://doi.org/10.1166/inn.2019.16359 (2019).

41. Kanimozhi, K., KhaleelBasha, S., SuganthaKumari, V. \& Kaviyarasu, K. Development and Characterization of Sodium Alginate/ Poly(vinyl alcohol) Blend Scaffold with Ciprofloxacin Loaded in Controlled Drug Delivery System. J Nanosci Nanotechno 19, 2493-2500, https://doi.org/10.1166/jnn.2019.16022 (2019).

42. Parasuraman, P. et al. Synthesis and antimicrobial photodynamic effect of methylene blue conjugated carbon nanotubes on E. coli and S. aureus (vol 18, pg 563, 2019). Photoch Photobio Sci 18, 592-592, https://doi.org/10.1039/c9pp90008j (2019).

43. Anju, V. T. et al. Antimicrobial photodynamic activity of rose bengal conjugated multi walled carbon nanotubes against planktonic cells and biofilm of Escherichia coli. Photodiagn Photodyn 24, 300-310, https://doi.org/10.1016/j.pdpdt.2018.10.013 (2018).

44. Hasan, I. et al. Eco-friendly green synthesis of dextrin based poly (methyl methacrylate) grafted silver nanocomposites and their antibacterial and antibiofilm efficacy against multi-drug resistance pathogens. J Clean Prod 230, 1148-1155, https://doi. org/10.1016/j.jclepro.2019.05.157 (2019).

45. Choo, J. H., Rukayadi, Y. \& Hwang, J. K. Inhibition of bacterial quorum sensing by vanilla extract. Lett Appl Microbiol 42, 637-641, https://doi.org/10.1111/j.1472-765X.2006.01928.x (2006).

46. Wagh, M. S. et al. Evaluation of anti-quorum sensing activity of silver nanowires. Appl Microbiol Biot 97, 3593-3601, https://doi. org/10.1007/s00253-012-4603-1 (2013).

47. Singh, B. R. et al. Mycofabricated biosilver nanoparticles interrupt Pseudomonas aeruginosa quorum sensing systems. Sci Rep-Uk 5, https://doi.org/10.1038/srep13719 (2015).

48. Garcia-Lara, B. et al. Inhibition of quorum-sensing-dependent virulence factors and biofilm formation of clinical and environmental Pseudomonas aeruginosa strains by ZnO nanoparticles. Lett Appl Microbiol 61, 299-305, https://doi.org/10.1111/lam.12456 (2015).

49. Pearson, J. P. et al. Structure of the Autoinducer Required for Expression of Pseudomonas-Aeruginosa Virulence Genes. $P$ Natl Acad Sci USA 91, 197-201, https://doi.org/10.1073/pnas.91.1.197 (1994).

50. Caraher, E., Reynolds, G., Murphy, P., McClean, S. \& Callaghan, M. Comparison of antibiotic susceptibility of Burkholderia cepacia complex organisms when grown planktonically or as biofilm in vitro. Eur J Clin Microbiol 26, 213-216, https://doi.org/10.1007/ s10096-007-0256-x (2007).

51. Al-Shabib, N. A. et al. Biofabrication of Zinc Oxide Nanoparticle from Ochradenus baccatus Leaves: Broad-Spectrum Antibiofilm Activity, Protein Binding Studies, and In Vivo Toxicity and Stress Studies. J Nanomater, https://doi.org/10.1155/2018/8612158 (2018). 
52. Al-Shabib, N. A. et al. Facile Synthesis of Tin Oxide Hollow Nanoflowers Interfering with Quorum Sensing-Regulated Functions and Bacterial Biofilms. J Nanomater 2018, 11, https://doi.org/10.1155/2018/6845026 (2018).

53. Al-Shabib, N. A. et al. Low Temperature Synthesis of Superparamagnetic Iron Oxide (Fe3O4) Nanoparticles and Their ROS Mediated Inhibition of Biofilm Formed by Food-Associated Bacteria. Front Microbiol 9, https://doi.org/10.3389/fmicb.2018.02567 (2018).

54. Parasuraman, P. et al. Antimicrobial photodynamic activity of toluidine blue encapsulated in mesoporous silica nanoparticles against Pseudomonas aeruginosa and Staphylococcus aureus. Biofouling 35, 89-103, https://doi.org/10.1080/08927014.2019.1570501 (2019).

55. Husain, F. M. et al. Broad-spectrum inhibition of AHL-regulated virulence factors and biofilms by sub-inhibitory concentrations of ceftazidime. Rsc Adv 6, 27952-27962, https://doi.org/10.1039/c6ra02704k (2016).

56. Cerca, N., Martins, S., Pier, G. B., Oliveira, R. \& Azeredo, J. The relationship between inhibition of bacterial adhesion to a solid surface by sub-MICs of antibiotics and subsequent development of a biofilm. Res Microbiol 156, 650-655, https://doi.org/10.1016/j. resmic.2005.02.004 (2005).

\section{Acknowledgements}

The authors are thankful to the Deanship of Scientific Research, King Saud University, Riyadh, for funding this work through Research Group No. RG -1439-089. The authors thank the Deanship of Scientific Research and RSSU at King Saud University for their technical support in the form of English language editing.

\section{Author contributions}

F.M.H. and A.A.A. conceived and designed experiments F.M.H., A.A.A., A.K., N.A. and A.B. performed experiments. F.M.H., A.A.A., A.K., A.B. and T.A.B. analyzed data. F.M.H., A.A.A., A.K., N.A. and T.A.B wrote the manuscript. All authors reviewed and approved the manuscript.

\section{Competing interests}

The authors declare no competing interests.

\section{Additional information}

Correspondence and requests for materials should be addressed to F.M.H. or A.A.A.

Reprints and permissions information is available at www.nature.com/reprints.

Publisher's note Springer Nature remains neutral with regard to jurisdictional claims in published maps and institutional affiliations.

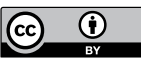

Open Access This article is licensed under a Creative Commons Attribution 4.0 International License, which permits use, sharing, adaptation, distribution and reproduction in any medium or format, as long as you give appropriate credit to the original author(s) and the source, provide a link to the Creative Commons license, and indicate if changes were made. The images or other third party material in this article are included in the article's Creative Commons license, unless indicated otherwise in a credit line to the material. If material is not included in the article's Creative Commons license and your intended use is not permitted by statutory regulation or exceeds the permitted use, you will need to obtain permission directly from the copyright holder. To view a copy of this license, visit http://creativecommons.org/licenses/by/4.0/.

(C) The Author(s) 2019 